
\title{
$\begin{array}{ll}\text { Research Square } & \begin{array}{l}\text { Preprints are preliminary reports that have not undergone peer review. } \\ \text { They should not be considered conclusive, used to inform clinical practice, } \\ \text { or referenced by the media as validated information. }\end{array}\end{array}$ \\ Impact of Climate on Tea Production: A Study of the Dooars Region in India
}

Piyashee Mallik ( $\nabla$ piyasheemallik@gmail.com )

Jadavpur University https://orcid.org/0000-0003-4127-9733

\section{Tuhin Ghosh}

Jadavpur University

\section{Research Article}

Keywords: Tea yield, Climate variables, Panel Data, Dooars region, Regression analysis, Climate model predictions

Posted Date: March 11th, 2021

DOl: https://doi.org/10.21203/rs.3.rs-276873/v1

License: (1) This work is licensed under a Creative Commons Attribution 4.0 International License. Read Full License

Version of Record: A version of this preprint was published at Theoretical and Applied Climatology on November 9th, 2021. See the published version at https://doi.org/10.1007/s00704-021-03848-x. 


\title{
Impact of Climate on Tea Production: A Study of the Dooars
} Region in India

\author{
Piyashee Mallik* and Tuhin Ghosh \\ School of Oceanographic Studies, Jadavpur University, Kolkata 700032, India
*Corresponding author: Piyashee Mallik, piyasheemallik@gmail.com, (+91) 9123329175, ORCID id: 0000-0003-4127-9733

\begin{abstract}
The Dooars region of West Bengal in India is a major tea producing region that contributes around $25 \%$ of the national tea yield. Changes in weather patterns along with the increased frequency of drought, storms, flood, etc. are likely to affect the tea industry adversely as tea production is reliant on the climate of the tea-growing region. In spite of the tea industry being the primary contributor of the Dooars economy, to date, the impact of climatic variables on tea yield in Dooars region remains unexplored. Here, we have developed a panel dataset that includes monthly data of the tea gardens of Dooars region over a 10-year period and statistically analysed the effects of climatic variables including temperature, precipitation, drought intensity, magnitude of warm-wet condition and precipitation intensity on tea yield. Overall, our seasonal analysis suggested that higher temperature during summer and monsoon seasons affected tea yield. Contrastingly, higher temperature during winter months and summer and winter rainfall were found to be beneficial for the increase in tea yield. An excessive and sporadic rainfall and a combination of hotter and wetter weather condition during monsoon months had a detrimental effect on tea yield. Finally, projections using climate models under different emission scenario predicted reduction of monsoon production under extreme carbon emission. The analyses and predictions of our study will be beneficial for tea garden managers of Dooars region in particular and northern India in general in adopting strategies to prevent the tea plantations from being affected due to climate change.
\end{abstract}

Keywords: Tea yield, Climate variables, Panel Data, Dooars region, Regression analysis, Climate model predictions.

\section{Acknowledgments}

This study would not have been possible without the permission, cooperation and assistance in data collection extended by the managers of the selected tea estates, personnel of the Dooars Branch Indian Tea Association (DBITA) and Tea Research Association, Nagrakata (TRA). The authors are grateful to Dr. Lalu Das and Dr. Javed Akhtar for their valuable inputs regarding climate model analyses. The authors also thank Mr. A. Rajan and Mr. Biman Saha from Tea Board of India (Kolkata) and Mr. Saunak Mitra of Goodricke Group Limited for their help during the entire course of this study. 


\section{Introduction}

Besides being the second most consumed beverage worldwide (Statista Research Department, 2016), the demand of tea in the world market has always been on the rise as an ideal liquid refreshment. The agriculture-based regional economies and livelihood options of the people of mainly Asian and African countries are dependent on plantation crops like tea for food supply, employment and earnings through exports (FAO, 2016). With a total production of 1344827 tonnes of tea ( $24 \%$ of the total tea produced globally), India secures the second position in the sector of tea. A total of 140.44 thousand hectares of land under tea enables West Bengal to become the second-best tea producing Indian state that contributes to almost 30\% of the national tea yield in India (FAO, 2016; Madhumitha, 2020). The TeraiDooars region in the northern part of West Bengal includes 380 established tea gardens and more than 20,000 small plantations that cumulatively cover around $25 \%$ of the national tea yield of India (Sarkar, 2018). Because of the climatic niche required for tea bush growth, the production of tea can undergo marked shifts due to fluctuations in the temperature conditions and precipitation pattern. The Dooars region, in terms of its location, tea production, total area under tea and contribution to Indian tea economy, calls for an in-depth analysis of the effects of the climatic variation in this region on the tea yield to uncover the challenges the tea industry here is encountering. In this paper by performing statistical analyses, we evaluated how tea yield in Dooars region is shaped by major climatic variables including monthly rainfall and temperature as well as extreme weather situations.

Climate change induced global warming has been regarded as the principal cause of $9-21 \%$ decline in the agricultural productivity of the developing nations like India (Cline, 2008). Tea [Camellia Sinensis (L.) O. Kuntze], a cash crop of immense importance, has been facing the brunt of the negative impacts of climate change. Although tea plants require a minimum annual rainfall between 1150 and $1400 \mathrm{~mm}$, the distribution of this rainfall over a month or an entire year has immense significance in the successful production of tea (M. K. V. Carr, 1972). For optimal growth, tea bushes need a minimum temperature between $12^{\circ} \mathrm{C}-13^{\circ} \mathrm{C}$ and an optimum temperature of $30^{\circ} \mathrm{C}$, above which the growth of tea bushes decline (M. K. V. Carr \& Stephens, 1992). Though the production of tea is projected to rise significantly over the next decade, there remains a potential hazard to the tea industry and associated livelihoods which are already reeling under the frequency of floods and droughts (Arthur, 2018). Since few geographical areas around the world harbour commercial tea growing, tea production becomes highly sensitive to the changes in temperature and precipitation patterns, recurrence of extreme events, and more.

In India, the agriculture sector is facing overawing challenges put forward by drastic changes in environmental conditions such as an average increase of $0.74^{\circ} \mathrm{C}$ in global temperature over the last century (Science, 2007). An approximate rise in global temperature by $3^{\circ} \mathrm{C}-5^{\circ} \mathrm{C}$ is projected in this century (U.N., 2018), indicating devastation calling for an urgent response. The 170 years old tea industry has a wholesome contribution to Indian economy (Goodwyn Tea, 2017). Unlike other countries, India manufactures both CTC and orthodox tea, as well as green tea (IBEF, 2018). Northeast Indian states of Assam and West Bengal and South Indian states of Tamil Nadu, and Kerala are the 
chief producers of this evergreen shrub. Darjeeling tea, the richest of all tea varieties, is registered as a Geographical Indication of India (Sharma, 2012). Nevertheless, the crux of the unequivocal issue of climate change in case of the tea production in India is that the industry remains a silent witness not only to the production upheavals in the recent past but also to the degraded quality of tea, shrinkage in the availability of suitable lands for cultivation and threatened livelihoods of the associated rural community. The simulation results of the FAO World Tea Model (based on the projected change in tea production in India and Sri Lanka to 2020) emphasized climate change as the main reason behind the gradual decline in tea production and more than $26 \%$ increase in international tea prices in these two nations (Chang, 2015).

Given the severe influence of climate on agriculture and crop production, several studies investigated tea bushes' vulnerability to the changing climate. Traditionally, how climatic variables influence tea shoot growth and quality of tea has been assessed through experimental field studies (M. K. V. Carr, 1972; De Costa et al., 2007). In a seminal study, Wijeratne (M. a Wijeratne, 1996) found that temperatures up to $22^{\circ} \mathrm{C}$ positively affect the shoot extension rate of tea bushes, but for temperature increase beyond that, the shoot extension rate exhibits a marked decline. Another study (Ahmed et al., 2014) uncovered the impact of frequent droughts on tea quality. Despite providing important insights on the mechanisms through which tea production can be impacted by climatic variations, such studies did not evaluate how the climatic variables directly impact the amount of tea produced.

To measure the direct impact of climatic variables on crop production, usually econometric analysis is performed using panel datasets of crop yield (Hsiang, 2016; Lobell \& Burke, 2010). Such models have been estimated for tea production as well. In a subsequent study, Wijeratne et al. (M. A. Wijeratne et al., 2007) concluded that increasing temperatures shall negatively affect tea yields at low and midelevations. Using panel data from Sri Lankan tea estates, Gunathilaka et al. (Gunathilaka et al., 2017) found that increased temperature and precipitation are expected to have damaging effects on tea industry of Sri Lanka. Lou et al. (Lou et al., 2013) analysed the trends of risk faced by three tea varieties in Longjing tea production area in China brought about by pick beginning date and frost damage. Boehm et al. (Boehm et al., 2016) predicted a reduction in tea production in China with a rise in daily precipitation and monsoon retreat. Carr and Stephens (M. K. V. Carr \& Stephens, 1992) identified the yield potentials of contrasting tea growing areas and important limiting factors in eastern Africa. Adhikari et al. (Adhikari et al., 2015) identified the shrinkage of suitable areas for tea farming due to rising temperatures in eastern Africa as the cause of a loss of yield of about $40 \%$ in the coming years.

India being home to a wide variety of tea, a handful of researches on the vulnerability of India's tea industry to climate change can be found as well. A study (Patra et al., 2013) exploring the tea production in Darjeeling concluded that the rise in average maximum temperature had a detrimental influence on tea yield, whereas relative humidity and rainfall were found to have positive correlations with tea production. The future of tea production in North-East India for 2050 predicted by Dutta (Dutta, 2014) suggested that with $2^{\circ} \mathrm{C}$ increase in average temperatures and modifications in the tea production period, changes in management practices would be the need of the hour so as to get accustomed to the climate 
change. Duncan et al. (Duncan et al., 2016) focused on Assam as their study area and found a negative correlation between increased monthly average temperature and tea yield.

The Dooars region of West Bengal accounts for the highest production of tea in West Bengal with a yield of 177.85 million kgs (FAO, 2016). Six tea gardens from the Dooars region in West Bengal found their place among the 14 best tea gardens of India (Siliguri Times, 2017). However, the tea industry of this region is not immune to the adverse impact of massive changes in temperature and precipitation patterns. The nearby Darjeeling tea industry has been hit hard by the increasing temperatures and decreasing rainfall and relative humidity in the last 20 years (Patra et al., 2013). Sporadic heavy rainfall, the shortening of the rainy season, and increasing temperatures are some of the striking events which the districts in the foothills of the Himalayas have been going through (Bullock, 2005). Even though the Terai-Dooars region of West Bengal contributes around 25\% of the national yield of India (Sarkar, 2018), to date, no evaluation of the possible effects of climatic variables on the tea production in functioning tea estates has been made. In order to address this knowledge gap, the present study delves into identifying how climatic variables influence tea production in the Dooars region of West Bengal through statistical analyses of panel dataset and future projections using several climate models so that climate-related threats faced by the tea gardens in this region can be made more vivid, tea plants are made more adaptive and the dwindling tea industry can be recovered in the face of massive environmental challenges.

\section{Data and methods}

\subsection{Study area}

The Dooars region of West Bengal comprises the tea-growing areas of Jalpaiguri, Alipuruduar and Coochbehar districts. While its northern portion is bounded by the district of Darjeeling, the state of Assam and Bangladesh are to its east and south respectively. Summer, Monsoon, and Post-monsoon (Winter) are the three primary seasons observed in this region. Generally, the region experiences maximum and minimum temperatures around $33^{\circ} \mathrm{C}$ and $10^{\circ} \mathrm{C}$ respectively. The months of May to September receive the larger part of the average annual rainfall (mean $\sim 3653 \mathrm{~mm}$ ). The northern fringe of Dooars region is ideal for tea-cultivation due to its favourable climate and topography and tea provides a large-scale employment (Tea Board \& Regional Remote Sensing Centre-East, 2013). This study focuses on the tea growing areas of Jalpaiguri and Alipurduar districts (Fig. 1a).

\subsection{Data compilation}

\subsubsection{Tea production and climatic variables}

For this study, 44 currently operational tea gardens in Dooars region were selected based on random spatial sampling. Only the gardens that keep a record of monthly tea yield, and have meteorological observatories of their own were selected. Tea bushes are plucked at an interval of seven to ten days. The quantity of the tea harvested essentially depends on the growth of new shoots and the rate of this growth (De Costa et al., 2007). We constructed a panel dataset consisting of monthly tea yield data for 
the selected 44 gardens for the period 2009 to 2018 (Fig. 1b). For each garden, the monthly tea yield data represented the tea production per unit area and was calculated as the ratio of the total weight $(\mathrm{kg}$. of green leaf and the area (ha) under tea plantation of that specific tea garden. As tea yield data was not available for some month-year combinations for some gardens, the panel dataset was unbalanced.

Data on climatic variables including temperature [average maximum temperature $\left({ }^{\circ} \mathrm{C}\right)$ and average minimum temperature $\left({ }^{\circ} \mathrm{C}\right)$ ] and rainfall (the amount of total rainfall and the number of rainy days in a month) used in this study were obtained from the meteorological observatories of the selected 44 tea gardens for the period 2009 - 2018 . Furthermore, the long-term data on these climatological variables from 1970 onwards for Jalpaiguri-Alipurduar districts (Fig. 1c) have been obtained from the Indian Meteorological Department (IMD).

\subsubsection{Projections due to climate change}

To predict the impact of future climatic conditions on tea production, we have used temperature and precipitation predictions from General Circulation Models (GCMs) from the Coupled Model Intercomparison Project phase 5 (CMIP5) experiment. Since climate predictions from a single GCM often contain random noise components (Akhter et al., 2017), we have adopted Multi Model Ensemble (MME) approach (Bellucci et al., 2015) for curtailing the noises by considering three GCMs namely MIROC5 (Model for Interdisciplinary Research on Climate, version 5), CCSM4 (Community Climate System Model, version 4) and CESM1-(CAM5) (Community Earth System Model version 1 that includes Community Atmospheric Model version 5). Past studies (Mishra et al., 2014; Sharmila et al., 2015; Watanabe et al., 2010) have identified MIROC5 as one of the most reliable models for the prediction of precipitation and temperature variables in the South Asian region. Moreover, Chaturvedi et al. (Chaturvedi et al., 2012) found the CCSM4 model to reliably predict these climate variables for India. As CESM1(CAM5) improves the predictions by CCSM4 by including larger $\mathrm{CO}_{2}$ radiative forcing and stronger shortwave feedbacks (Meehl et al., 2013), it has also been considered.

Climate change predictions for all three GCMs were obtained from the CMIP5 data website hosted by the Earth System Grid Federation (ESGF) - Lawrence Livermore National Laboratory (https://esgfnode.llnl.gov/projects/esgf-llnl/) based on three emission scenarios [Representative Concentration Pathways (RCP)] : 2.5, 4.5, and 8.5 as specified by the Fifth assessment report of IPCC (AR5). RCPs correspond to the total bandwidth of future greenhouse emission trajectories where the numbers denote the increase of radiative forcing consequent upon greenhouse gas emissions reached by 2100 . While RCPs 2.6, 4.5, and 8.5 correspond to low, medium, and extreme carbon emission scenarios respectively. For each model for different RCPs, three different time-horizons were considered - 2021-2039, 20402059, and 2060-2079 and the first ensemble member (rilp1) was selected to obtain the climate predictions for the Dooars area. For bias correction against observed data, for each model, simulations of climate variables for the time-window 2006-2019 were obtained. The reference observational data for the Dooars region was obtained from IMD gridded datasets (http://www.imdpune.gov.in/). To eliminate the systematic errors (biases) arising in the GCMs due to limited spatial resolution, scaling- 
based bias correction (Wetterhall et al., 2012) was performed on the climate model predictions. For temperature variables, the monthly projections were bias corrected by shifting by the mean bias during the reference time window (2006-2019). For precipitation, monthly projections were bias corrected by multiplicative scaling with the ratio of the observed and model predicted values during the reference period.

\subsection{Methods}

\subsubsection{Statistical analyses using panel dataset}

In this study, a production-unit-specific panel data has been constructed based on monthly tea yield and climatic variables to analyze the effects of climatic variables on tea production. However, certain timeinvariant differences (tea cultivar, elevation, soil quality, slope, management expertise being some of the time-invariant unobserved factors) between production units are likely to bias the results. To remove these biases, a tea garden-specific effect has been considered. The average economic life span of the tea bushes is 50-60 years. Past studies have shown that different varieties of tea have distinct responses to stressors related to climate (De Costa et al., 2007). To avoid the case of this varietal switching, a 10year database (2009-2018) has been used assuming that clonal switching is unlikely within a 10-year period. Apart from this, the 10-year period is likely to minimize the possible influences of certain timevarying unobserved factors namely the change in varieties of tea, management strategies taken up by the tea garden authorities on tea production. Moreover, this study includes month and year fixed effects that denote monthly and yearly variations in tea production that are recurrent across all tea gardens.

Based on the monthly meteorological and production data from 44 tea gardens under study, the impact of climate change on tea yield has been analyzed considering the following four conditions -

i) maximum and minimum average temperature and precipitation,

ii) drought,

iii) warm-wet situation, and

iv) precipitation intensity.

\section{i) Maximum and minimum average temperature and precipitation:}

To evaluate the impact of temperature and precipitation on tea yield, a fixed-effect production function was estimated using the following regression model

$$
\begin{aligned}
\ln \left(y_{g m y}\right)=\alpha_{g} & +\delta_{m}+\delta_{y}+\beta_{1} T_{g m y}^{\max }+\beta_{2} T_{g m y}^{\min }+\beta_{3}\left(T_{g m y}^{\max }\right)^{2}+\beta_{4}\left(T_{g m y}^{\min }\right)^{2}+\beta_{5} P_{g m y}+\beta_{6} P_{g m y}^{2} \\
& +\varepsilon_{g m y}
\end{aligned}
$$

For month $m$ of year $y, y_{g m y}$ denotes the tea yield in the garden $g$. In the production function, the natural logarithm of the monthly tea yield serves as the dependent variable and the climatic variables serve as the independent predictor variables. The regression coefficients $\left(\beta_{i}\right)$ denote the percentage shift 
in tea yield with a unit change in the corresponding predictor variable. $T^{\max }$ and $T^{\min }$ denote maximum and minimum average temperature respectively and $P$ denotes the monthly total rainfall. The regression model also includes the quadratic terms of $T^{\max }, T^{\min }$ and $P$ as independent variables to account for any nonlinear effect of temperature and rainfall on tea yield. Since tea is harvested sequentially throughout the year, each year under analysis has been divided into three distinct seasons, namely, Summer Season (March to May), Monsoon Season (June to September) and Post-Monsoon/Winter Season (October to December). The months of January and February have been excluded due to low yields in all the tea gardens. The variable $\alpha_{g}$ controls for time-invariant garden-specific unobserved effects on tea yield for garden $g$. To account for month-specific and year-specific fixed effects on tea production that are common across all gardens, a month-specific variable $\delta_{m}$ and a year-specific variable $\delta_{y}$ have been included in the model. Apart from analyzing the impact of climatic variables of the current month on tea yield, we estimated another model where one-month lag for each of $T^{\max }$, $T^{\text {min }}$ and $P$ were considered as independent variables to account for the time required for tea shoot growth to reach harvestable stage (M. K. V. Carr, 1972). The regression models were estimated using ' $\mathrm{l} \mathrm{m}$ ' function implemented in $\mathrm{R}$ version 3.6.3. For validating the models, 5 -fold cross-validation was performed where the original data was divided into 5 equal sized groups. The model was trained on data from 4 groups and the other group was used as a test set for evaluating the model. To validate the model, the training and testing phases were repeated 5 times using each of the 5 groups as the test set. The cross-validation was performed using 'caret' package (Kuhn, 2015) (implemented in R version 3.6.3).

\section{ii) Drought:}

More than $66 \%$ of India's geographical area is exposed to frequent occurrences of drought (Birthal et al., 2015). Extended periods of high temperature and substantial rainfall deviation from the normal that reduces the availability of moisture lead to the occurrence of drought events thereby affecting agricultural crops (Fontes et al., 2017; GOI, 2016). To evaluate the impact of drought events, a drought index was developed based on the methods of Babcock and Birthal (Birthal et al., 2015; Yu \& Babcock, 2010), which computes the product of two main parameters, viz., monthly positive standardized temperature irregularities and monthly negative standardized rainfall irregularities that capture the degree of hotness (unusually high temperatures) and dryness (abnormally low rainfall) respectively. The monthly standardized temperature $\left(T D_{g m y}^{s d}\right)$ and rainfall $\left(P D_{g m y}^{s d}\right)$ irregularities are given by:

$$
T D_{g m y}^{S d}=\frac{T_{g m y}^{m a x}-T_{m}^{\text {normal }}}{S D(T)_{m}}, P D_{g m y}^{S d}=\frac{P_{g m y}-P_{m}^{\text {normal }}}{S D(P)_{m}}
$$

Where $T_{m}^{\text {normal }}$ and $P_{m}^{\text {normal }}$ represent the long term mean values of maximum average temperature and rainfall respectively. $S D(T)_{m}$ and $S D(P)_{m}$ denote long-term standard deviations of maximum average temperature and rainfall respectively. The calculation of the long term means and standard deviations of these two parameters includes the years from 1970 to 2018. In order to associate an 
increment in drought index score with a corresponding escalation in drought intensity, the drought index has been transformed into positive values by multiplying it by negative one.

$$
D I_{g m y}=\left\{-\min \left(0, P D_{g m y}^{s d}\right) * \max \left(0, T D_{g m y}^{s d}\right)\right\}
$$

For month $m$ of year $y, D I_{g m y}$ denotes the drought index for garden $g$. The effect of drought intensity has been estimated by incorporating drought index as the predictor variable in the regression model given by :

$$
\ln \left(y_{g m y}\right)=\beta D I_{g m y}+\alpha_{g}+\delta_{m}+\delta_{y}+\epsilon_{g m y}
$$

The model was validated using 5-fold cross-validation.

\section{iii) Warm-wet situation:}

An analysis of the long-term monsoon rainfall in India reveals a hike in the number of extreme weather events such as alternating phases of intense precipitation and not enough rainfall. Since tea plants can get affected by excess rainfall and temperature increase above an optimal value (Dutta, 2014), the impact of warm-wet condition (temperature and precipitation higher than normal) on tea yield was estimated by computing a warm-wet index. The warm-wet index was computed as a product of monthly positive standardized temperature irregularities and monthly positive standardized rainfall irregularities given by

$$
W W I_{g m y}=T D_{g m y}^{s d} * P D_{g m y}^{s d}
$$

For analysing the warm-wet condition, only those data points for which both temperature deviation $\left(T D_{g m y}^{s d}\right)$ and rainfall deviation $\left(P D_{g m y}^{s d}\right)$ are positive were considered. As a result, the value of warmwet index is always positive and an increase in warm-wet index can be interpreted as an indicator of increased warm-wet condition corresponding to higher temperature and moisture stress. The following regression model was estimated that uses the warm-wet index as an independent variable:

$$
\ln \left(y_{g m y}\right)=\beta W W I_{g m y}+\alpha_{g}+\delta_{m}+\delta_{y}+\epsilon_{g m y}
$$

For month $m$ and year $y, y_{g m y}$ denotes the tea yield for garden $g . W W I_{g m y}$ denotes the warm-wet index in garden $g$ for month $m$ and year $y$. The model was validated using 5-fold cross-validation.

\section{iv) Precipitation intensity:}

Precipitation intensity (PI) is defined as the amount of precipitation (in this case rainfall), received per unit time interval (Lanza et al., 2005). In this case PI has been calculated by dividing the amount of rainfall received in a month by the sum of rainy days of that month. A day is treated as a rainy day if the amount of daily rainfall surpasses $1 \mathrm{~mm}$ (Revadekar \& Preethi, 2012). The higher the value of precipitation intensity, a measure of the sporadic rainfall, the more sporadic is the rainfall. Duncan et al. (Duncan et al., 2016) have reported a negative correlation between the precipitation intensity and monthly tea yield. In order to investigate the possible influence of PI on tea yield, we selected the data 
points that had greater rainfall as compared to the long-term average. How tea yield is shaped by precipitation intensity was estimated using the regression model:

$$
\ln \left(y_{g m y}\right)=\beta P I_{g m y}+\alpha_{g}+\delta_{m}+\delta_{y}+\epsilon_{g m y}
$$

For garden $g$, the tea yield for month $m$ and year $y$ is denoted by $y_{g m y} . P I_{g m y}$ denotes the precipitation intensity in garden $g$ for month $m$ and year $y$. The model was validated using 5-fold cross-validation.

\subsubsection{Impact of climate change on tea production}

To predict the impact of climate change on tea production, ensemble average $\left(V_{a v g}^{f u t}\right)$ for each climate variable $(V)$ was first computed as a simple average of GCM predictions where each GCM was equally weighted:

$$
V_{\text {avg }}^{f u t}=\frac{1}{k} \sum_{i=1}^{k} V_{i}^{f u t}
$$

where $k$ denotes the number of climate models considered ( 3 for us), and $V_{i}^{f u t}$ denotes the prediction of the climate variable $V$ by the $i^{\text {th }} \mathrm{GCM}$ under a specific emission scenario and time period. Assuming $V^{\text {cur }}$ to denote the climate variable for the current period (averaged over the years 2009-2018), the proportional impact of the change in climate variable on tea production for a specific RCP and timehorizon is given by:

$$
P P I_{V}=\beta_{V} \Delta V+\beta_{V^{2}} \Delta V\left(V_{\text {avg }}^{f u t}+V^{c u r}\right)
$$

In Eq. 8, $P P I_{V}$ denotes the predicted proportional impact for change in climate variable $V, \Delta V=$ $V_{a v g}^{f u t}-V^{c u r}$ denotes the predicted change in climate variable $V$, and $\beta_{V}$ and $\beta_{V^{2}}$ denote the regression coefficients estimated from Eq. 1 for the climate variable $V$ and its quadratic terms respectively. The aggregate impact (AI) on tea production for a specific climate change scenario as predicted by the considered GCMs for a time-horizon is computed by:

$$
A I=\sum_{V \in\left\{T^{\max }, T^{\min }, P\right\}} P P I_{V}
$$

\section{Results}

\subsection{Impact of temperature and precipitation}

In estimating the regression model with pooled data that includes all months from March to December, the regression coefficient for monthly average maximum temperature was positive and statistically significant and the corresponding quadratic term was negative and statistically significant. Fig. 2a illustrates the marginal effect of average maximum temperature on tea yield considering the observed range of maximum temperatures averaged over a month. With an increase in average maximum temperature of current month, a decreasing trend in this positive effect on tea yield was observed (Fig. 2a). Apart from pooled data, three seasonal models (summer, monsoon and winter) have also been estimated. For summer and monsoon seasons, the effect of average maximum temperature of current 
month was not statistically significant. For winter months, this positive effect decreased with an increase in average maximum temperature owing to the negative regression coefficient for the corresponding quadratic term (Online Resource 1: Supplementary Fig. 1e, Table 1).

Fig. $2 b$ shows that the average minimum temperature has a similar effect on tea yield as average maximum temperature for pooled data analysis (positive and statistically significant for linear term; negative and statistically significant for quadratic term). The seasonal analyses revealed that for summer months, average minimum temperature had an adverse impact on tea yield (Online Resource 1: Supplementary Fig. 1a), the extent of which decreased with an increase in average minimum temperature (owing to positive regression coefficient of the quadratic term). For monsoon season, average minimum temperature did not bear any statistically significant effect on tea yield. The winter months showed the same trend (Online Resource 1: Supplementary Fig. 1f) as the pooled analysis (Table 1).

Fig. 2c illustrates the impact of rainfall on tea yield, the regression coefficient of rainfall based on pooled data was found to be positive and statistically significant, whereas the corresponding quadratic term was negative and statistically significant. The effect of rainfall was statistically significant for all the three seasons. For summer (Online Resource 1: Supplementary Fig. 1b) and winter months (Online Resource 1: Supplementary Fig. 1d), increased rainfall corresponded to increasing tea yield returns, whereas tea yield during the monsoon months exhibited decreasing returns (Online Resource 1: Supplementary Fig. 1c) to increased monthly rainfall (Table 1).

The pooled linear model considering the first-order lagged (previous month) climatic variables as predictors indicated that precipitation of the previous month had a positive statistically significant effect on tea yield (Fig. 3). This positive statistically significant effect was observed across all three seasons (Table 2, Supplementary Fig. 2c, 2d, 2h). In contrast, the quadratic term for previous month's precipitation had a negative statistically significant effect for the pooled data as well as all three seasons. For pooled data analyses, temperature variables of the previous month did not have any statistically significant effect on tea yield. For summer season, both average maximum and minimum temperature of the previous month had a detrimental effect on tea yield (statistically significant) (Supplementary Fig. 2a, 2b), but the regression coefficients for the quadratic terms were positive. For monsoon season, only average maximum temperature of the previous month had a significant effect on tea yield and the effect was negative (Supplementary Fig. 2e). For winter season, both average maximum and minimum temperature of the previous month had a positive statistically significant effect on tea yield (Supplementary Fig. 2f, 2g). Among the quadratic terms, only the average minimum temperature term had a statistically significant effect and it was negative.

\subsection{Impact of drought}

The impact of drought was estimated by pooling data for hotter months (comparatively higher temperature) i.e. April to October. The pooled data analysis showed that tea production in Dooars region was not susceptible to drought for the years considered in this study as evidenced by the not statistically 
significant regression coefficient for drought index. The model indicated a negative drought index coefficient for April, May, June and July denoting a negative relationship between the intensity of drought and tea yield. However, this negative association was statistically significant for May only (Online Resource 1: Supplementary Table 1).

\subsection{Impact of warm-wet situation}

369

As climate warming leading to high temperature and extreme precipitation events can affect crop production (Bengtsson, 2010; Chou et al., 2013; Lesk et al., 2016), the effect of a weather condition that is simultaneously warmer and wetter compared to the normal was estimated by pooling datapoints for which both temperature and rainfall were higher than their long-term average. The pooled analysis revealed that the warm-wet condition was related with a statistically significant decrease in tea yield. The seasonal analyses further denoted that for monsoon months (June to September), the regression coefficient for the warm-wet index term was negative as well as statistically significant (Table 3). This indicates that a combination of high temperature and high rainfall during monsoon months hampers tea production.

\subsection{Impact of precipitation intensity}

The pooled analysis (considering datapoints with rainfall higher than the long-term average and months with total rainfall $>1 \mathrm{~mm}$ ) did not find any overall statistically significant effect of precipitation intensity on tea yield. However, in case of seasonal analyses (considering summer and monsoon months), precipitation intensity had a negative bearing on tea yield during monsoon months i.e., June to September and this effect was also statistically significant. This indicates that sporadic heavy rainfall during the monsoon season hampers tea yield (Table 2). This also explains the findings of the previous analysis (Table 1, Online Resource 1: Supplementary Fig. 1c) and the negative impact of total precipitation on tea yield during monsoon months can be partially attributed to the irregularity of the heavy rainfall during these months.

\subsection{Future projections on tea production}

Average maximum and minimum temperature and precipitation for three seasons (summer, monsoon and winter) were predicted for the Dooars region for three time-horizons - 2021-2039, 2040-2059, and 2060-2079 - for different emission scenarios (RCP2.6, RCP4.5 and RCP8.5) using MIROC5, CCSM4 and CESM1(CAM5) as shown in Online Resource 1: Supplementary Table 2. All three models predicted maximum and minimum temperature for each season to increase for all time horizons for most emission scenarios. However, the amount of increase differed across GCMs. Also for some seasons for some RCPs, the maximum temperature was predicted to be similar or lower compared to the current values. Prediction of precipitation was found to vary a lot across RCPs and climate models. MIROC5 predicted monsoon precipitation to decrease under RCP8.5 but winter precipitation to increase for time-horizons 2021-2039 and 2060-2079. CCSM4 predicted monsoon precipitation to increase for each RCP but summer precipitation to decrease under most conditions. CESM1(CAM5) 
also predicted monsoon and winter precipitation to increase for all RCPs and summer precipitation to decrease for most RCPs. For the extreme emission scenario (RCP8.5), CESM1(CAM5) predicted a $170 \%$ increase in monsoon precipitation.

After estimating the ensemble average of predictions of climate variables by different climate models, we estimated the mean proportional impact of predicted climate change on tea production under different emission scenarios. Table 4 shows the mean estimates for proportional impact of change in climate variables on tea production under RCPs 2.6, 4.5 and 8.5 for three time periods (2021-2039, 2040-2059, and 2060-2079). The proportional impacts were calculated for each season (summer, monsoon and winter) separately based on the regression coefficients estimated from our seasonal analyses. For all time periods, proportional impacts of maximum temperature was estimated to be negative for monsoon season but mostly positive for summer and winter season. For all seasons for all time horizons, proportional impact of minimum temperature was estimated to be positive. In contrast, proportional impact of precipitation was negative for most specifications, however, those impacts were 1-2 orders of magnitude lower as compared to that of the temperature variables. For different time horizons, the aggregate impact was found to vary the most for winter season expecting a wide range of aggregate impact from 1.2\% production reduction during 2021-2039 (RCP 2.6) to 39\% production increase during 2060-2079 for RCP8.5. Aggregate impact on monsoon production was close to zero in most cases with production reduction expected during 2021-2039 and 2040-2059 under extreme emission scenario. Mean aggregate impact on summer production was mostly positive under different specifications.

\section{Discussion}

Using a combination of a panel dataset of garden-specific monthly per-hectare tea yield and monthly measurements of climatic variables, in this study, we have performed multiple regression analyses to assess the impact of climatic variations on tea production in the Dooars region. Our analyses show that overall an increase in monthly average maximum and minimum temperatures have facilitated tea yield in the past 10 years. However, the positive impact reduces with an increase in temperature and above a certain threshold $\left(30.78^{\circ} \mathrm{C}\right.$ and $23.13^{\circ} \mathrm{C}$ for the average maximum and minimum temperatures respectively) warming negatively affects tea yield. In contrast, the previous month's temperature variables were found to have no significant impact in pooled analysis. The seasonal analysis revealed that increased monthly maximum and minimum temperatures (for both current and previous month) during post-monsoon months (October-December) help autumn flush tea yield. Contrastingly during summer months (March-May), an increase in average minimum temperature of the current month and increase in average maximum and minimum temperature of the previous month negatively affect first and second flush tea production. These results conform with previous experimental studies (M. K. V. Carr, 1972; Green, 1971) that showed that the temperature range $21^{\circ} \mathrm{C}-29^{\circ} \mathrm{C}$ positively impacts tea shoot extension. The tea cultivars harvested in the Dooars region are hybrids between Chinese and Assam varieties. For a similar hybrid tea clone, net photosynthesis has been observed to be maximum at $25^{\circ} \mathrm{C}$ and to sharply decrease above $30^{\circ} \mathrm{C}$ (Joshi \& Palni, 1998). The lowering in tea yield due to an 
increase in monthly average minimum temperature during summer months can be attributed to an increase in leaf temperature which in turn reduces net photosynthesis for hybrid tea clones (Patel et al., 2019).

Our analysis further revealed that the total precipitation of current as well as previous month overall had a more or less positive impact on tea production (smaller effect compared to temperature). Total precipitation of the current month also had a significant effect on tea production in all three seasons. While it facilitated tea production during summer and winter months, greater monthly rainfall during monsoon months (June-September) negatively affected rain flush. A similar beneficial effect of rainfall on tea production during dry months has also been observed in past studies (Sen et al., 1966). The adverse impact of increased monsoon rainfall that we found from our analysis is coherent with an earlier study (Nemec-Boehm et al., 2014) on the Chinese tea ecotype. Our results showed that rain flush tea yield got affected due to rainfall variability (sporadic rainfall as quantified by precipitation intensity) during monsoon months. Different explanations have been provided in literature for the detrimental effect of higher precipitation intensity on tea production - a) increased cloud cover leads to a reduction in solar radiation, affects tea shoot development by damaging tender buds (M. K. V. Carr, 1972; M. A. Wijeratne et al., 2007) and finally impedes the growth of tea bushes (Nemec-Boehm et al., 2014), and b) higher rainfall variability poses a difficulty for tea harvesting (Ahmed et al., 2014; Boehm et al., 2016). Precipitation intensity has been found to affect tea production in Assam (Duncan et al., 2016) and Sri Lanka (Gunathilaka et al., 2017) as well.

Our analysis showed that tea yield in Dooars area was not sensitive to drought events, only the production of the month of May was affected due to drought event, which can be attributed to reduced rainfall and an increase in minimum average temperature (Table 1), as these climatic variables had significant effects on tea yield during summer months. Different tea varieties are known to have different susceptibilities to drought (M. K. V. Carr \& Stephens, 1992), with var. Sinensis known to be more drought-resistant compared to var. Assamica (De Costa et al., 2007).

Just like drought, other extreme events such as excessive rainfall can also lead to a reduction of crop yield ( $\mathrm{Li}$ et al., 2019) and a warmer climate contributes to an increase in precipitation variability (Pendergrass et al., 2017) and thus can increase the frequency of sporadic heavy rainfall. Our evaluation of the effect of the combination of hotter and wetter climate on tea yield showed that the warm-wet condition had a detrimental effect on tea yield. Specifically, the rain flush tea yield during monsoon season was negatively impacted when high temperature accompanied heavy rainfall. Due to shallow rooting, the growth of tea bushes is susceptible to changes in soil moisture level which can fluctuate due to precipitation variability. A combination of warmer temperature and dry spell can result in soil water content being much below the field capacity (M. K. V. Carr \& Stephens, 1992) which can further lead to reduced shoot growth and delayed bud breaking (M. K. V Carr, 2000; Fordham, 1970). Our finding on the negative effect of the warm-wet condition and precipitation variability during monsoon 
months is consistent with previous studies (Duncan et al., 2016; Gunathilaka et al., 2017) reporting tea yield loss due to temperature rise and changing precipitation patterns.

Finally, we also estimated the proportional impact of climate change on tea yield in Dooars region using multi-model ensemble projections of future climate under different emission scenario for short-term (2021-2039), medium-term (2040-2059) and long-term (2060-2079) time horizons from the observed period. The climate model projections estimated the impacts of individual climate variables as well as an aggregate impact which indicated a reduction in monsoon production under extreme carbon emission scenario.

There are a few caveats in our study which should be explained properly so that the results are interpreted correctly. Firstly, we limit our analyses to the effect of drought and precipitation intensity while considering the adverse effects different extreme weather events pose on tea production. Besides, due to the non-availability of data, we cannot include the influence of monsoon onset and retreat dates which might have important influence on tea yield (Boehm et al., 2016; Nemec-Boehm et al., 2014). Secondly, other variables including humidity, wind speed, soil temperature, solar radiation, and the duration of sunshine hours that can influence tea yield (M. K. V. Carr \& Stephens, 1992) have not been considered in the present study and will be investigated in future. Thirdly, although garden-specific fixed effects have been included in our models to control for unobservable factors like the type of tea being cultivated, type and amount of fertilizer and pesticides used, technological variation in the manufacturing stages etc., there is a chance that these factors can bias our results. Fourthly, our estimates do not consider the effect of carbon fertilization which can fetch positive results in tea production (Reilly et al., 1996).

Nevertheless, our study is a valuable addition to the interdisciplinary field of climatic variables and tea production as it is the first study to adjudge the effect of changing climate on a major tea producing region of India which has remained completely unexplored till now. Considering the economic and social significance of tea globally, further research is warranted in this area taking into account those factors which have not been discussed in this study.

\section{Conclusion}

This study remains useful when focus is on how climatic variables and their variations consequent upon climate change bear striking imprints on the production of agricultural (in this case, tea) crops. Moreover, this study provides a micro-level analysis of the relationship between climatic variables and tea production based on a tea-estate level dataset compiled from the tea estates of a major tea producing region of India. Our results suggest that an increase in summer and monsoon temperature and excessive and erratic rainfall during the monsoons as consequences of climate change are detrimental for tea yield. Similarly, rain flush tea production in monsoon was also found to be affected by a combination of hotter and wetter weather as caused by climate change. These findings shall prove to be beneficial for tea garden managers and tea garden workers in adopting economical strategies to prevent the tea production 
in this region from being affected due to changing climate. The estate-level dataset generated in this study shall make further research in this area more convenient giving enough scope for the betterment of the tea industry in the Dooars region.

\section{Declarations}

\section{Conflict of Interest}

515 The authors have no conflicts of interest to declare that are relevant to the content of this article.

\section{$516 \quad$ Funding Statement}

517 This work was partially funded by Swami Vivekananda Single Girl Child Scholarship

518 conducted by University Grants Commission (UGC) to P.M.

\section{Author's contributions}

520 P.M and T.G designed the overall plan of the study. P.M collected the data, performed data analysis and prepared the figures and tables. Both the authors wrote the manuscript and approved the final version.

\section{Availability of data and material}

The panel dataset used in this study is available upon request. The climate model projections are freely available from Earth System Grid Federation (ESGF) - Lawrence Livermore National Laboratory (https://esgf-node.llnl.gov/projects/esgf-llnl/).

\section{Code availability}

The codes for statistical analyses performed in this study were implemented in $\mathrm{R}$ v3.6.3. The

\section{Ethics approval}

Not applicable. No human subjects were involved in this research.

\section{Consent to participate}

Not applicable. No human subjects were involved in this research.

\section{Consent for publication}

Not applicable. No human subjects were involved in this research.

\section{$\underline{\text { References }}$}

Adhikari, U., Nejadhashemi, A. P., \& Woznicki, S. A. (2015). Climate change and eastern Africa: A review of impact on major crops. Food and Energy Security, 4(2), 110-132. https://doi.org/10.1002/fes3.61

Ahmed, S., Stepp, J. R., Orians, C., Griffin, T., Matyas, C., Robbat, A., Cash, S., Xue, D., Long, C., Unachukwu, U., Buckley, S., Small, D., \& Kennelly, E. (2014). Effects of extreme climate events on tea (Camellia sinensis) functional quality validate indigenous farmer knowledge and 
sensory preferences in Tropical China. PLoS ONE, 9(10). https://doi.org/10.1371/journal.pone.0109126

551

552

Akhter, J., Das, L., \& Deb, A. (2017). CMIP5 ensemble-based spatial rainfall projection over homogeneous zones of India. Climate Dynamics. https://doi.org/10.1007/s00382-016-3409-8

Arthur, B. R. (2018). Tea production rises: but FAO warns of climate change threat. https://www.beveragedaily.com/Article/2018/05/30/Tea-production-rises-but-FAO-warns-ofclimate-change-threat?utm_source=copyright\&utm_medium=OnSite\&utm_campaign=copyright

Bellucci, A., Haarsma, R., Gualdi, S., Athanasiadis, P. J., Caian, M., Cassou, C., Fernandez, E., Germe, A., Jungclaus, J., Kröger, J., Matei, D., Müller, W., Pohlmann, H., Salas y Melia, D., Sanchez, E., Smith, D., Terray, L., Wyser, K., \& Yang, S. (2015). An assessment of a multimodel ensemble of decadal climate predictions. Climate Dynamics. https://doi.org/10.1007/s00382-014-2164-y

Bengtsson, L. (2010). The global atmospheric water cycle. In Environmental Research Letters. https://doi.org/10.1088/1748-9326/5/2/025202

Birthal, P. S., Negi, D. S., Khan, M. T., \& Agarwal, S. (2015). Is Indian agriculture becoming resilient to droughts? Evidence from rice production systems. Food Policy, 56, 1-12. https://doi.org/10.1016/j.foodpol.2015.07.005

Boehm, R., Cash, S. B., Anderson, B. T., Ahmed, S., Griffin, T. S., Robbat, A., Stepp, J. R., Han, W., Hazel, M., \& Orians, C. M. (2016). Association between empirically estimated monsoon dynamics and otherweather factors and historical tea yields in China: Results from a yield response model. Climate, 4(2), 1-19. https://doi.org/10.3390/cli4020020

Bullock, P. (2005). Climate Change Impacts. Encyclopedia of Soils in the Environment, 4, 254-262. https://doi.org/10.1016/B0-12-348530-4/00089-8

Carr, M. K. V. (1972). The climatic requirements of the tea plant: A review. Experimental Agriculture, 8(1), 1-14. https://doi.org/10.1017/S0014479700023449

Carr, M. K. V., \& Stephens, W. (1992). Climate, weather and the yield of tea. In Tea. https://doi.org/10.1007/978-94-011-2326-6_4

Carr, M. K. V. (2000). Shoot growth plus plucking equals profit. TRIT Occasional Publication.

Chang, K. (2015). Socio-economic implications of climate change for tea producing countries. Food and Agriculture Organization of the United Nations, 7.

Chaturvedi, R. K., Joshi, J., Jayaraman, M., Bala, G., \& Ravindranath, N. H. (2012). Multi-model climate change projections for India under representative concentration pathways. Current Science. 
582

583

584

585

586

587

588

589

590

591

592

593

594

595

596

597

598

599

600

601

602

603

604

605

606

607

608

609

610

611

612

613

Chou, C., Chiang, J. C. H., Lan, C. W., Chung, C. H., Liao, Y. C., \& Lee, C. J. (2013). Increase in the range between wet and dry season precipitation. Nature Geoscience. https://doi.org/10.1038/ngeo1744

Cline, W. R. (2008). Global warming and agriculture. Finance and Development. https://doi.org/10.1002/9780470752630.ch18

De Costa, W. A. J. M., Mohotti, A. J., \& Wijeratne, M. A. (2007). Ecophysiology of tea. In Brazilian Journal of Plant Physiology. https://doi.org/10.1590/S1677-04202007000400005

Duncan, J. M. A., Saikia, S. D., Gupta, N., \& Biggs, E. M. (2016). Observing climate impacts on tea yield in Assam, India. Applied Geography, 77, 64-71. https://doi.org/10.1016/j.apgeog.2016.10.004

Dutta, R. (2014). Climate change and its impact on tea in northeast India. Journal of Water and Climate Change, 5(4), 625-632. https://doi.org/10.2166/wcc.2014.143

FAO. (2016). Report of the working group on climate change of the FAO intergovernmental group on tea. In Food and Agriculture Organization of the United Nations.

Fontes, F. P., Gorst, A., \& Palmer, C. (2017). Does choice of drought index influence estimates of drought-induced cereal losses in India? GRI Working Papers.

Fordham, R. (1970). Factors affecting tea yields in Malawi. Annual Report, 71--130.

GOI. (2016). Drought Management Manual. 154. http://agricoop.nic.in/sites/default/files/Manual Drought 2016.pdf

Goodwyn Tea. (2017). THE IMPORTANCE AND INFLUENCE OF TEA INDUSTRY IN INDIA. https://www.goodwyntea.com/blogs/news/the-importance-and-influence-of-tea-industry-in-india

Green, R. (1971). Weather and the seasonal growth of tea in Malawi. University of Nottingham.

Gunathilaka, R. P. D., Smart, J. C. R., \& Fleming, C. M. (2017). The impact of changing climate on perennial crops: the case of tea production in Sri Lanka. Climatic Change, 140(3-4), 577-592. https://doi.org/10.1007/s10584-016-1882-z

Hsiang, S. (2016). Climate Econometrics. Annual Review of Resource Economics. https://doi.org/10.1146/annurev-resource-100815-095343

IBEF. (2018). Tea Industry And Exports In India. Ibef. https://www.ibef.org/exports/indian-teaindustry.aspx

Joshi, S. C., \& Palni, L. M. S. (1998). Clonal variation in temperature response of photosynthesis in tea. Plant Science. https://doi.org/10.1016/S0168-9452(98)00015-6

Kuhn, M. (2015). Caret: classification and regression training. Ascl, ascl--1505. 
Lanza, L. G., Leroy, M., Alexandropoulos, C., Stagi, M., \& Wauben, W. (2005). WMO LABORATORY INTERCOMPARISON OF De Bilt ( The Netherlands ) Genoa ( Italy) Trappes ( France) September 2004 - September 2005. September 2004.

Lesk, C., Rowhani, P., \& Ramankutty, N. (2016). Influence of extreme weather disasters on global crop production. Nature. https://doi.org/10.1038/nature16467

Li, Y., Guan, K., Schnitkey, G. D., DeLucia, E., \& Peng, B. (2019). Excessive rainfall leads to maize yield loss of a comparable magnitude to extreme drought in the United States. Global Change Biology, 25(7), 2325-2337. https://doi.org/10.1111/gcb.14628

Lobell, D. B., \& Burke, M. B. (2010). On the use of statistical models to predict crop yield responses to climate change. Agricultural and Forest Meteorology. https://doi.org/10.1016/j.agrformet.2010.07.008

Lou, W., Sun, K., Sun, S., Ma, F., \& Wang, D. (2013). Changes in pick beginning date and frost damage risk of tea tree in Longjing tea-producing area. Theoretical and Applied Climatology, 114(1-2), 115-123. https://doi.org/10.1007/s00704-012-0825-5

Madhumitha, J. (2020). Tea production volume across India in financial year 2019, by state. Statista. https://www.statista.com/statistics/868978/india-tea-production-volume-by-state/

Meehl, G. A., Washington, W. M., Arblaster, J. M., Hu, A., Teng, H., Kay, J. E., Gettelman, A., Lawrence, D. M., Sanderson, B. M., \& Strand, W. G. (2013). Climate change projections in CESM1(CAM5) compared to CCSM4. Journal of Climate. https://doi.org/10.1175/JCLI-D-1200572.1

Mishra, V., Kumar, D., Ganguly, A. R., Sanjay, J., Mujumdar, M., Krishnan, R., \& Shah, R. D. (2014). Reliability of regional and global climate models to simulate precipitation extremes over India. Journal of Geophysical Research. https://doi.org/10.1002/2014JD021636

Nemec-Boehm, R. L., Cash, S. B., Anderson, B. T., Ahmed, S., Griffin, T. S., Orians, C. M., Robbat, A. J., Stepp, R. A., \& Han, W. (2014). Climate change, the monsoon, and tea yields in China. Annual Meeting of the Agricultural and Applied Economics Association, Minneapolis, July, 118.

http://search.proquest.com/docview/1697444696?accountid=10297\%5Cnhttp://sfx.cranfield.ac.u k/cranfield?url_ver=Z39.88-

2004\&rft_val_fmt=info:ofi/fmt:kev:mtx:journal\&genre=preprint\&sid=ProQ:ProQ:abiglobal\&ati tle=Climate+change, + the + monsoon, + and + tea + yields

Patel, P. K., Zhang, D., Borthakur, D., Hazarika, M., Boruah, P., Barooah, R., Sabhapondit, S., Neog, N. J., \& Gogoi, R. C. (2019). Quality Green Tea (Camellia sinensis L.) Clones Marked through Novel Traits. Beverages. https://doi.org/10.3390/beverages5040063

Patra, P. S., Bisen, J. S., Kumar, R., Choubey, M., Mazumdar, A. B., Singh, M., \& Bera, B. (2013). 
Pendergrass, A. G., Knutti, R., Lehner, F., Deser, C., \& Sanderson, B. M. (2017). Precipitation variability increases in a warmer climate. Scientific Reports, 7(1), 1-9. https://doi.org/10.1038/s41598-017-17966-y

Reilly, J., Baethgen, W., Chege, F. E., Geijn, van de S. C., Lin Erda, Iglesias, A., Kenny, G., Patterson, D., Rogasik, J., Rötter, R., Rosenzweig, C., Sombroek, W., Westbrook, J., Bachelet, D., Brklacich, M., Dämmgen, U., \& Howden, M. (1996). Agriculture in a changing climate: impacts and adaptation. In Impacts, adaptations and mitigation of climate change: scientifictechnical analyses. Cambridge (UK), Cambridge Univ. Press.

Revadekar, J. V., \& Preethi, B. (2012). Statistical analysis of the relationship between summer monsoon precipitation extremes and foodgrain yield over India. International Journal of Climatology. https://doi.org/10.1002/joc.2282

Sarkar, D. (2018). Bright first flush tea output is expected to be followed by even brighter second flush. https://economictimes.indiatimes.com/news/economy/agriculture/bright-first-flush-teaoutput-is-expected-to-be-followed-by-even-brighter-second-flush/articleshow/63934753.cms

Science, I. / W. G. (2007). [Climate change 2007] : The physical science basis : summary for policymakers and technical summary and frequently asked questions ; part of the Working Group I contribution to the Fourth Assessment Report of the Intergovernmental Panel on Climate Change. Proceedings of the Alpine Snow Workshop, Munich, October 5-6, Germany | HeBIS-Verbundkatalog, 8, 142. http://bluemarble.nasa.gov.

Sen, A. R., Biswas, A. K., \& Sanyal, D. K. (1966). The Influence of Climatic Factors on the Yield of Tea in the Assam Valley. In Journal of Applied Meteorology (Vol. 5, Issue 6, pp. 789-800). https://doi.org/10.1175/1520-0450(1966)005<0789:tiocfo>2.0.co;2

Sharma, C. (2012). Darjeeling Tea: Indian Geographical Indication. https://www.iipta.com/darjeeling-tea-indian-geographical-indication/

Sharmila, S., Joseph, S., Chattopadhyay, R., Sahai, A. K., \& Goswami, B. N. (2015). Asymmetry in space-time characteristics of Indian summer monsoon intraseasonal oscillations during extreme years: Role of seasonal mean state. International Journal of Climatology. https://doi.org/10.1002/joc.4100

Siliguri Times. (2017). 6 Dooars garden among the best tea gardens 'list. https://archive.siliguritimes.com/?p=26715

Statista Research Department. (2016). Annual per capita tea consumption worldwide as of 2016, by leading countries. https://www.statista.com/statistics/507950/global-per-capita-teaconsumption-by-country/ 
Tea Board, K., \& Regional Remote Sensing Centre-East, N. (2013). Tea Garden Atlas, Jalpaiguri District. In Government of India, Ministry of Commerce and Industry.

Tea Board Of India. (1995). Techno-Economic Survey of Dooars Tea Industry.

U.N. (2018). Global temperatures on track for 3-5 degree rise by 2100: U.N. - Reuters. Reuters, 1-9. https://www.reuters.com/article/us-climate-change-un/global-temperatures-on-track-for-3-5degree-rise-by-2100-u-n-idUSKCN1NY186

Watanabe, M., Suzuki, T., O’Ishi, R., Komuro, Y., Watanabe, S., Emori, S., Takemura, T., Chikira, M., Ogura, T., Sekiguchi, M., Takata, K., Yamazaki, D., Yokohata, T., Nozawa, T., Hasumi, H., Tatebe, H., \& Kimoto, M. (2010). Improved climate simulation by MIROC5: Mean states, variability, and climate sensitivity. Journal of Climate. https://doi.org/10.1175/2010JCLI3679.1

Wetterhall, F., Pappenberger, F., He, Y., Freer, J., \& Cloke, H. L. (2012). Conditioning model output statistics of regional climate model precipitation on circulation patterns. Nonlinear Processes in Geophysics. https://doi.org/10.5194/npg-19-623-2012

Wijeratne, M. A., Anandacoomaraswamy, A., Amarathunga, M. K. S. L. D., Ratnasiri, J., Basnayake, B. R. S. B., \& Kalra, N. (2007). Assessment of impact of climate change on productivity of tea (Camellia sinensis L.) plantations in Sri Lanka. Journal of the National Science Foundation of Sri Lanka, 35(2), 119-126. https://doi.org/10.4038/jnsfsr.v35i2.3676

Wijeratne, M. a. (1996). Vulnerability of sri lanka tea production. Water, Air and Soil Pollution, 92, 87-94. https://doi.org/10.1007/BF00175555

Yu, T., \& Babcock, B. A. (2010). Are U.S. corn and soybeans becoming more drought tolerant? American Journal of Agricultural Economics. https://doi.org/10.1093/ajae/aaq074

\section{Figure Legends}

Fig. 1 (a) Map of Jalpaiguri and Alipurduar districts showing the study area. The green triangles denote the locations of the tea gardens from which the data were collected. (b) Monthly average tea production $(\mathrm{Kg} / \mathrm{Hectare})$ for the selected tea gardens in Dooars region. The average production of each month is computed over 10 years (2009-2018) for each garden. (c) Average monthly maximum (red solid line) and minimum temperatures (orange dotted line) and monthly precipitation (blue bar) of the Dooars region. The average values have been computed from 1970-2018 using IMD gridded temperature and precipitation (rainfall) datasets

Fig. 2 (a) Marginal effect of monthly maximum average temperature on tea yield (logarithmic scale); (b) Marginal effect of monthly minimum average temperature on tea yield (logarithmic scale); and (c) Marginal effect of monthly precipitation on tea yield (logarithmic scale). The Y-axis shows the predicted log yield, while the $\mathrm{X}$-axis on each graph spans the range of maximum and minimum temperature and precipitation values observed in the pooled dataset. The shaded regions represent $95 \%$ confidence interval. Three lines corresponding to different values of square of temperature and precipitation ranges are displayed 
723 Fig. 3 Marginal effect of total precipitation of previous month on tea yield (logarithmic scale).

724 The Y-axis shows the predicted log yield, while the $\mathrm{X}$-axis spans the range of precipitation 725 values observed in the pooled dataset. The shaded regions represent $95 \%$ confidence interval. 726 Three lines corresponding to different values of square of precipitation ranges are displayed 

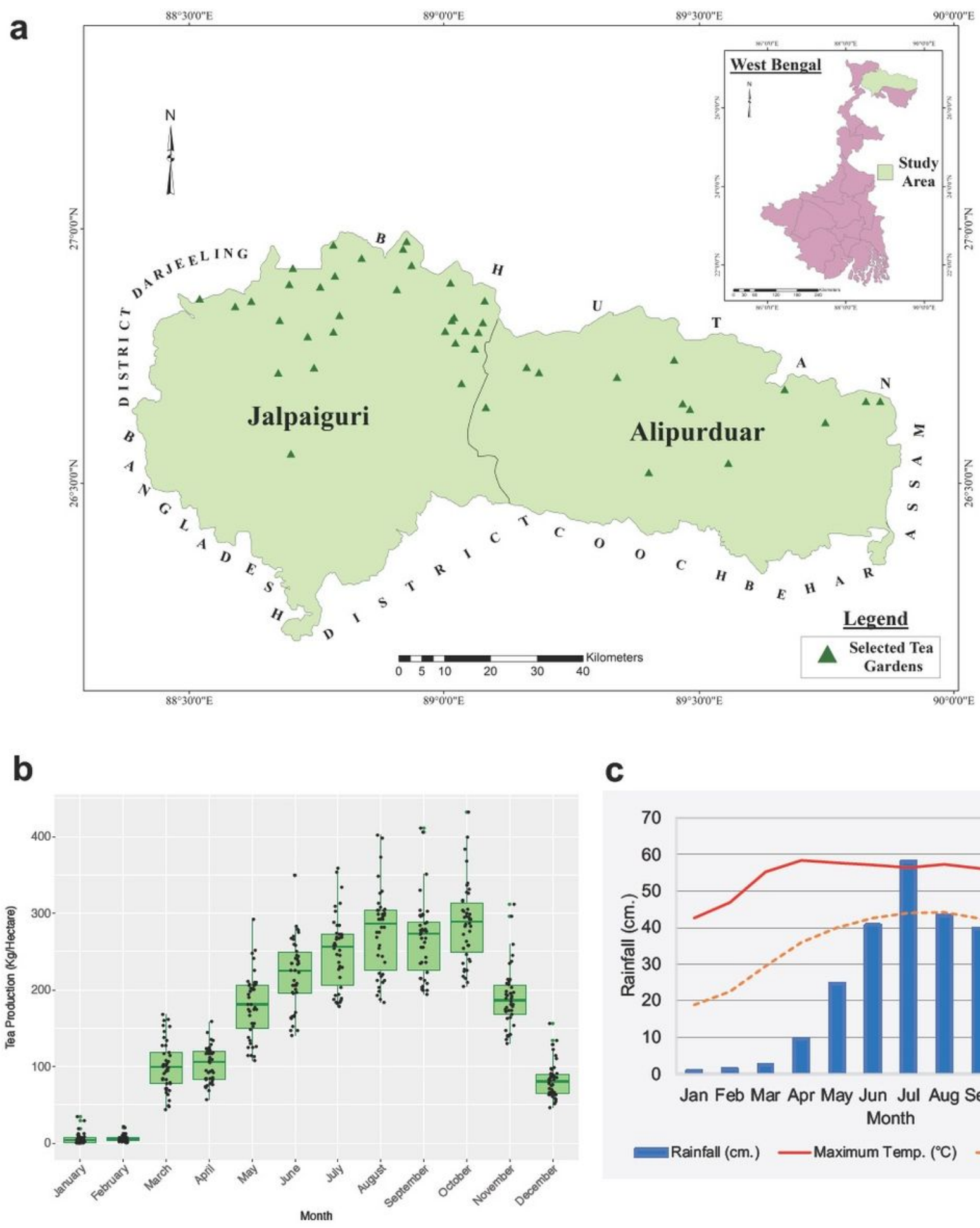

C

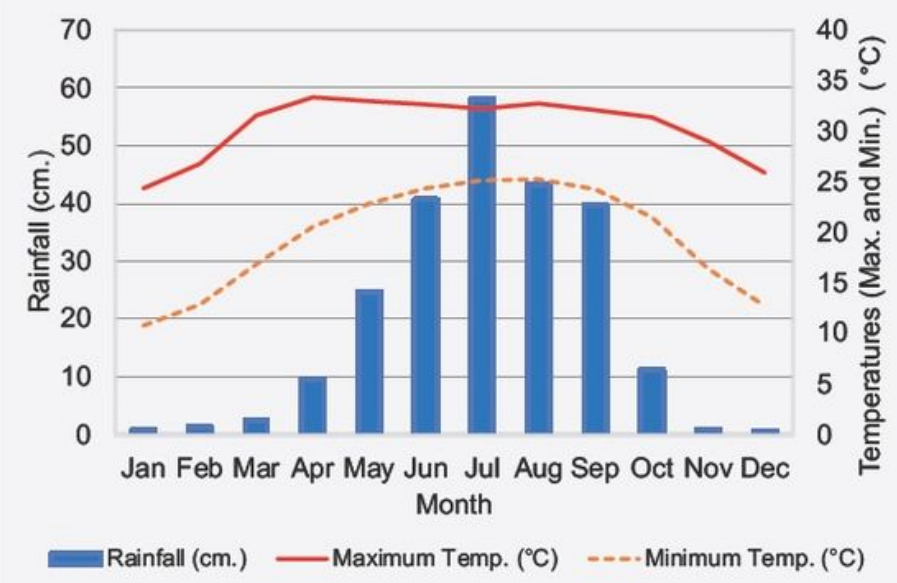

\section{Figure 1}

(a) Map of Jalpaiguri and Alipurduar districts showing the study area. The green triangles denote the locations of the tea gardens from which the data were collected. (b) Monthly average tea production $(\mathrm{Kg} /$ Hectare) for the selected tea gardens in Dooars region. The average production of each month is 
computed over 10 years (2009-2018) for each garden. (c) Average monthly maximum (red solid line) and minimum temperatures (orange dotted line) and monthly precipitation (blue bar) of the Dooars region. The average values have been computed from 1970-2018 using IMD gridded temperature and precipitation (rainfall) datasets. Note: The designations employed and the presentation of the material on this map do not imply the expression of any opinion whatsoever on the part of Research Square concerning the legal status of any country, territory, city or area or of its authorities, or concerning the delimitation of its frontiers or boundaries. This map has been provided by the authors.
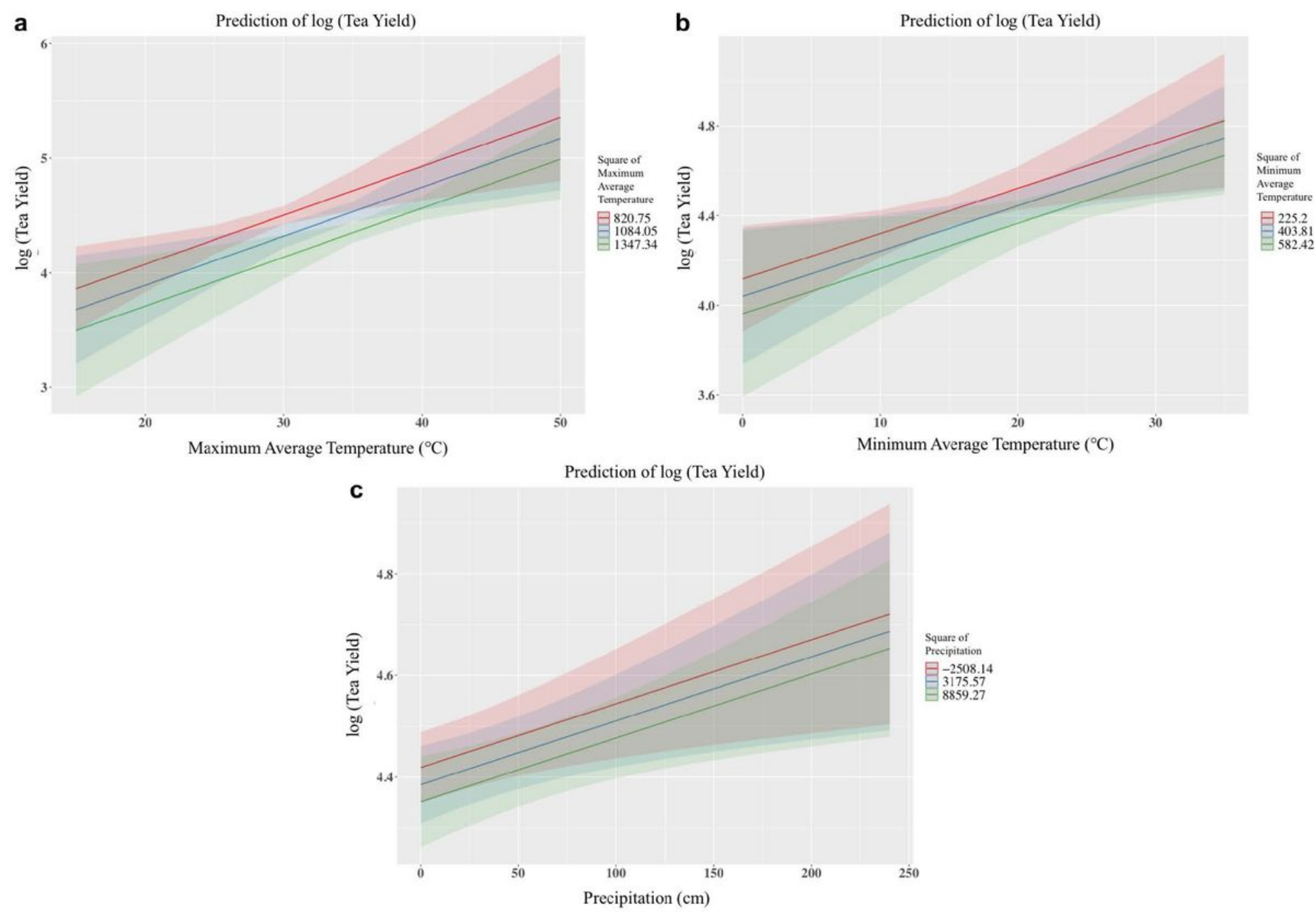

\section{Figure 2}

(a) Marginal effect of monthly maximum average temperature on tea yield (logarithmic scale); (b) Marginal effect of monthly minimum average temperature on tea yield (logarithmic scale); and (c) Marginal effect of monthly precipitation on tea yield (logarithmic scale). The Y-axis shows the predicted log yield, while the $\mathrm{X}$-axis on each graph spans the range of maximum and minimum temperature and precipitation values observed in the pooled dataset. The shaded regions represent $95 \%$ confidence interval. Three lines corresponding to different values of square of temperature and precipitation ranges are displayed 


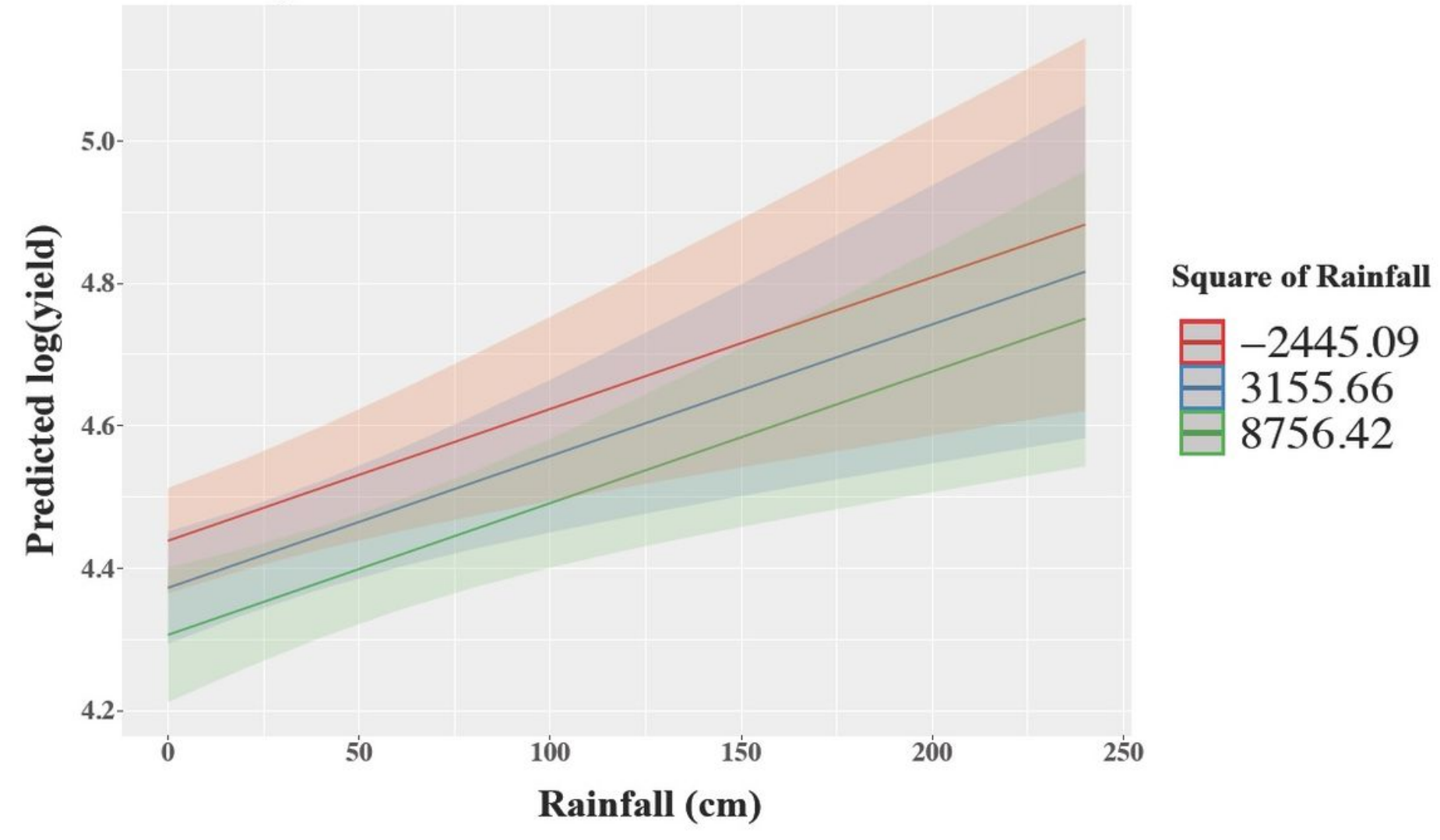

Figure 3

Marginal effect of total precipitation of previous month on tea yield (logarithmic scale). The Y-axis shows the predicted log yield, while the X-axis spans the range of precipitation values observed in the pooled dataset. The shaded regions represent $95 \%$ confidence interval. Three lines corresponding to different values of square of precipitation ranges are displayed

\section{Supplementary Files}

This is a list of supplementary files associated with this preprint. Click to download.

- ESM1.docx 